\title{
Association of depression with epilepsy
}

\author{
Bihari $\mathrm{TH}^{1}$, Rakesh $\mathrm{M}^{2}$, Mohit $\mathrm{S}^{2}$, Steve $\mathrm{T}^{3}$ \\ 1.Associate Professor, 2. PG Trainees, 3. House Officer, Dept. Of Psychiatry, Regional Institute Of Medical \\ Sciences, Imphal.
}

\begin{abstract}
Many epilepsy clinics are mainly concerned with seizure control, treatment and neurological deficits with epilepsy but it is vitally important that we are able to recognize the symptoms of anxiety and, in particular, those of depression. Depression lowers quality of life significantly yet it is an eminently treatable condition. Depression can directly increase seizure frequency through the mechanism of sleep deprivation; failure to recognize depression or inadequate treatment can lead to suicide. Besides this; peri-ictal expression of depression or some time atypical expression of depression is seen in epileptic patients. Depression also often worsens concordance with antiepileptic medication. Multifactorial variables play a pathogenic role in the high comorbid occurrence of these two disorders.Animal models of depression in which the kindling process is facilitated. Neurobiological aspects and data from structural and functional neuroimaging studies in humans provide a further understanding of potential common pathogenic mechanisms operant in depression and epilepsy that may explain their high comorbidity.
\end{abstract}

Key Words: Depression, Epilepsy, Peri-ictal depression, Neurobiological aspect, Neuroimaging studies, comorbidity.

\section{Introduction}

A complex relation between the two conditions has been demonstrated in research studies, which suggests that the high comorbidity of depression with epilepsy. Yet, despite its high prevalence, depression remains under recognized and undertreated. People with epilepsy experience depression at two to three times the rate of the general population [1] and are more likely to experience depression than people with other chronic conditions [2].This means that while these depressive feelings can be partly due to the stress of living a chronic condition, they are mainly caused by the same abnormal brain activity that normally occurs with seizures[3].

\section{Epidemiology}

The conditions coexist in a significant number of patients. Indeed, some authors estimate the lifetime prevalence of depression in association with epilepsy to be as high as $35 \%$.studies examined the link between the laterality of epilepsy and depression and relationships between epilepsy and suicide, including the link with anti-epileptic drugs(AED) $[3,4]$, the FDA published results of a statistical analysis of the relationship between AEDs and suicidality, leading manufacturers to alter their data and information sheets with specific warnings about depression and suicidal behaviors [5]. Wiegartz et al. found that $43 \%$ of 76 patients with epilepsy had a major depressive disorder (MDD) and that $38 \%$ of patients with lifetime histories of MDD never had been referred for treatment, while $68 \%$ of the patients with a minor depression were untreated [6]. In a study of 97 children and adults with epilepsy and a depressive disorder severe enough to warrant pharmacotherapy, Kanner et al. determined that $63 \%$ of patients with spontaneous depression and $54 \%$ of patients with an iatrogenic depression were symptomatic for more than 1 year before treatment was initiated [7]. Ettinger et al. identified symptoms of depression in $26 \%$ of 44 children with epilepsy - all were undiagnosed and untreated [8]. Data from three population-based control studies indicate that people with a history of depression have a 4- to 7-fold higher risk of developing epilepsy [9-11]; in one of these studies, a prior history of suicide was associated with a 5 -fold increased risk of developing epilepsy [11].The bidirectional relationship does not imply causality but rather suggests that common pathogenic mechanisms are operant in both conditions, with the presence of one disorder potentially facilitating the development of the other.

\section{Peri-Ictal Episodes Of Depression}

Peri-ictal clusters of symptoms and episodes, which usually last from a few hours to a few days, may occur. It is possible that peri-ictal symptoms to some degree account for the atypical manifestations of the depressive disorders in patients with epilepsy. Pre-ictal symptoms or episodes typically present as a dysphoric mood that precedes a seizure by several hours to days [12]; it becomes more accentuated during the 24 hours prior to the seizure and remits post-ictally or persists for a few days after the seizure. Post-ictal symptoms can be elusive, as symptom free periods of 1 to 5 days can exist between the seizure and onset of psychiatric symptoms. 


\section{Atypical Depression In Epileply}

The atypical presentation of depressive disorders in people with epilepsy has been recognized for a long time. Kraepelin [13] and then Bleuler [14] were the first authors to describe a pleomorphic pattern of symptoms that included affective symptoms consisting of prominent irritability intermixed with euphoric mood, fear, and symptoms of anxiety, as well as anergia, pain, and insomnia. Gastaut [15] confirmed Kraepelin and Bleuler's observations, leading Blumer to coin the term "interictal dysphoric disorder" to refer to this type of depression in epilepsy [16].

\section{History Of Depression And Postsurgical Seizure Outcome}

Kanner et al. investigated the role of a lifetime history of depression as a predictor of postsurgical seizure outcome [39]. Using a multivariate logistic regression model, the investigators evaluated the covariates of a lifetime history of depression, cause of temporal lobe epilepsy (i.e., mesial temporal sclerosis, lesional, or idiopathic), duration of seizure disorder, and occurrence of generalized tonic-clonic seizures. They found that a lifetime history of depression was the sole predictor of persistent auras in the absence of disabling seizures, while the cause of the temporal lobe epilepsy and a lifetime history of depression were both significant predictors of failure to achieve freedom from disabling seizures .It raises the question of whether a history of depression may be a marker of a more severe form of epilepsy.

\section{Neurobiological Aspects}

A hyperactive hypothalamic-pituitary-adrenal axis (HPA) is most likely one of the potential pathogenic mechanisms explaining this co-morbidity. In fact, the dexamethasone suppression test was the first biological marker of major depressive disorders (MDD) in humans and has been recently demonstrated in patients with temporal lobe epilepsy [17].In animal models of epilepsy[18] Using the lithium and pilocarpineinduced status epilepticus model, Mazarati et al. demonstrated an increase of corticosteroid (CS) serum concentrations during the interictal period, which also correlated with the severity of equivalent symptoms of depression[18]. Corticosteroids have been found to decrease the binding of 5HT, one of the neurotransmitters that play a pivotal pathogenic role in depression.

Furthermore, experimental studies with rats and monkeys have demonstrated that corticosteroid has a neurotoxic effect at high concentrations in following regions of brain:

(1) damage of hippocampal neurons, specially in pyramidal cell layer of hippocampus, mediated by reduction of dendritic branching and loss of dendritic spines that are included in glutamatergic synaptic inputs.

(2) interference with neurogenesis of granule cells in the adult hippocampal dentate gyrus [19-21]. Result in structural changes in the dentate gyrus, pyramidal cell layer of hippocampus, amygdala and temporal neocortex [19-22].

(3) decreased levels of brain-derived neurotrophic factor (BDNF) reversed by long-term administration of antidepressants.

(4) In the frontal lobes, high corticosteroid secretion has been associated with a decrease in glial cell numbers in subgenual, cingulated and dorsolateral sections of the prefrontal cortex [23-27].

As reported in adult studies on stressors and precipitants of seizures, poor quality and reduced quantity of sleep during period of stress were related to an increase in seizure frequency. But sleep deprivation can directly affect people having depression, and it leads to a vicious cycle involving stress, depression, sleep deprivation, and seizure [37].Studies are clearly warranted to delineate the mechanisms underlying the complex relationship among stress, depression, sleep deprivation and seizure to identify how best to intervene to stop this vicious cycle with epilepsy.

In epilepsy, the pathogenic role of the excitatory neurotransmitter glutamate has been established for a long time. Pathogenic role of glutamate in depressive disorder is shown in following points:

(1) dysfunction of glutamate transporter proteins in depression.

(2) antidepressant effects of glutamate receptor antagonists .As like NMDA antagonist ketamine has shown antidepressant effects [40] .And riluzole (2-amino-6-(trifluoromethoxy) benzothiazole) which has a mechanism of action consisting of inhibition of glutamate receptors, but it also has effects on AMPA receptor trafficking and glutamate reuptake. The antidepressant effects of this drug were suggested [41].

(3) abnormal concentrations of cortical glutamate and GABA identified with functional neuroimaging studies using proton magneticresonance spectroscopy (H1-MRS) and neuropathologic studies [28,29].

(4)In animal models of depression, glutamatergic dysfunction has been suggested to be related to disturbance of glutamate transporters (vGluT1 and excitatory amino acid transporters EAAT-1, EEAT-2 (found primarily in glial cells), EEAT-3 (localized principally in neurons) and EEAT-4 (localized in the cerebellum) [28-30]. 


\section{Neuroimaging Studies Of Depression In Epileptic Patients}

Efforts to image cerebral biomarkers of psychiatric comorbidities in persons with epilepsy began two decades ago Although we do not yet have evidence to support the use of neuroimaging in the diagnosis of psychiatric disorders in individuals with epilepsy, we do have data regarding the association of imaging abnormalities of specific brain regions with symptoms of depression and anxiety One of the initial studies of cerebral metabolism and depression in patients with partial seizures was performed by Bromfield et al. nearly [31]The investigators compared activity of 18fluoro-2- deoxyglucose positron emission tomography (FDGPET) in nine individual brain regions to depression symptoms assessed by the Beck Depression Inventory (BDI).Kanner et al. found Functional abnormalities(identified by positron emission tomography [PET] and single-photon emission computed tomography [SPECT]) in temporal and frontal lobes, consisting of decreased 5-HT1A binding in the mesial structures, raphe nuclei, thalamus, and cingulate gyrus[38].

Hippocampal abnormalities have been variably associated with depression in persons with epilepsy. An early study by Quiske et al. found that subjects with hippocampal sclerosis had higher BDI scores than those with temporal lobe epilepsy with no hippocampal abnormality [32].

Some imaging modalities have offered insights into the relationship of epileptogenicity of limbic structures and depression. For example, decreased N-acetyl aspartate (NAA) on MR spectroscopy has been associated with regions of increased spike rate and seizure onset on EEG [33-34]. A study of MR spectroscopy and depression in 31 subjects with temporal lobe epilepsy found that the extent of voxels in the hippocampi with decreased NAA was linearly associated with severity of depression symptoms [35]. Several studies using serotonin receptor ligands for PET have yielded important insights into the neurobiology of depression in temporal lobe epilepsy.

Although the associations of aspects of depression with brain dysfunction in epilepsy are complex, research utilizing advanced neuroimaging techniques is improving our understanding of affective disorders in persons with recurrent seizures.

\section{Antiepileptic Drugs And Depression}

Patients taking antiepileptic medication may become depressed as a result of their treatment. Sadly, data from drug trials are often unhelpful since the symptoms reported - for example, nervousness, abnormal thinking - are non-specific. The antiepileptic drugs most closely associated with acute depression on initiation of treatment are hydantoins, succinimides, clonazepam, phenytoin, vigabatrin, phenobarbitone, and topiramate. Some antiepileptics, on the other hand, can support antidepressant treatment are carbamazepine, valproate and lamotrigine [36]. Depression with topiramate may be linked to abrupt cessation of seizures or drug toxicity. Patients starting tiagabine may develop symptoms of agitation, withdrawal, and mood disturbance suggestive of depression; depression is reported with tiagabine but it is essential that such patients undergo an electroencephalogram (EEG) to exclude tiagabine associated non-convulsive status epilepticus.

\section{Conclusion}

Patients face multiple obstacles associated with a life with seizures. Time to time patients have to suffer directly due to seizures and indirectly due to its consequences which affect patients' quality of life. The relatively high comorbidity between depression and epilepsy is not only the expression of chronicity but data presented in this review suggest the existence of common neurobiologic pathogenic mechanisms between depression and epilepsy. The impact of these pathogenic mechanisms is not restricted to high comorbidity, but may play a pivotal role on the worse course and response to pharmacologic and surgical treatment of seizure disorders of patients with a lifetime history of depression. Whether early recognition and treatment of depressive disorders would change the impact on the higher risks that patients with depression have of developing epilepsy and on their response to therapy remains to be established.

\section{REFERENCES}

[1] Temkin O. The falling sickness. Baltimore: Johns Hopkins University Press; 1950

[2] Robertson MM, Trimble MR. Depressive illness in patients with epilepsy: a review.Epilepsia 1983;24(Supplement 2):S109-16

[3] Robertson MM, Trimble MR. Depressive illness in patients with epilepsy: a review.Epilepsia 1983;24(Supplement 2):S109-16

[4] Robertson MM. Suicide and epilepsy. In: Engel J, et al, editor. Epilepsy, a comprehensivetext book.New York: Raven Press; 1996. p. 2141-52

[5] FDA, US Department of Health and Human Services. Statistical review andevaluation: antiepileptic drugs and suicidality; May 23 2008. Washington.

[6] Wiegartz P, Seidenberg M, Woodard A, Gidal B, Hermann B. Co-morbid psychiatric disorder in chronic epilepsy: recognition and etiology of depression. Neurology 1999;53(suppl 2):S3-S8

[7] Kanner AM, Kozak AM, Frey M. The use of sertraline in patientswith epilepsy: is it safe? Epilepsy Behav 2000; 1:100-105.

[8] Ettinger AB, Weisbrot DM, Nolan EE, Gadow KD, Vitale SA,Andriola MR, Lenn NJ, Novak GP, Hermann BP. Symptomsof depression and anxiety in pediatric epilepsy patients. Epilepsia 1998; 39:595-599.

[9] Forsgren L,NystromL. An incident case referent study of epilepticseizures in adults. Epilepsy Res 19990;6:66-81.

[10] Hesdorffer DC, Hauser WA, Annegers JF, Cascino G. Majordepression is a risk factor for seizures in older adults. Ann 
Neurol2000;47:246-249.

[11] Hesdorffer DC,HauserWA,Olafsson E, Ludvigsson P, Kjartansson O.Depression and suicidal attempt as risk factor for incidental unprovoked seizures. Ann Neurol 2006;59:35-41.

[12] Blanchet P, Frommer GP. Mood change preceding epileptic seizures. J Nerv Ment Dis 1986;174:471-476.

[13] Kraepelin E. Psychiatrie, vol 3. Leipzig: Johann Ambrosius Barth,1923.

[14]. Bleuler E. Lehrbuch der Psychiatrie. 8th ed. Berlin: Springer, 1949.

[15] Gastaut H, Morin G, Les'evre N. 'Etude du comportement des'epileptiques psychomoteurs dans l'intervalle de leurs crises: lestroubles de l'activit'e globale et de la sociabilit'e. Ann Med Psychol(Paris) 1955;113:1-27.

[16] Blumer D, Altshuler LL. Affective disorders. In: Epilepsy: A ComprehensiveTextbook, vol. II (Engel J, Pedley TA, eds.) Philadelphia:Lippincott-Raven, 1998:2083-2099.unprovoked seizures. Ann Neurol 2006;59:35-41.

[17] Zobel A, Wellmer J, Schulze-Rauschenbach S, et al. Impairment of inhibitorycontrol of the hypothalamic pituitary adrenocortical system in epilepsy. Eur Arch Psychiatry Clin Neurosci 2004;254(5):303-11.

[18] Mazarati AM, Shin D, Kwon YS, et al. Elevated plasma corticosterone level and depressive behaviour in experimental temporal lobe epilepsy. Neurobiol Dis 2009; 34(3):457-61.

[19] Sapolsky RM. Glucocorticoids and hippocampal atrophy in neuropsychiatric disorders. Arch Gen Psychiatry 2000;57:925-35 (b).

[20] Shirayama Y, Chen AC, Nakagawa S, Russell DS, Duman RS. Brain-derived neurotrophi factor produces antidepressant effects in behavioral models of depression. J Neurosci 2002;15(22(8)):3251-61.

[21] Bowley MP, Drevets WC, Ongur D, Price JL. Low glial numbers in the amygdala in major depressive disorder. Biol Psychiatry 2002;52:404-12.

[22] Rajkowska G, Miguel-Hidalgo JJ, Wei J, et al. Morphometric evidence for neurona and glial prefrontal cell pathology in major depression. Biol Psychiatry 1999;45(9):1085-98.

[23] Cotter DR, Pariante CM, Everall IP. Glial cell abnormalities in major psychiatric disorders: the evidence and implications. Brain Res Bull 2001;55:585-95.

[24] Cotter DR, Pariante CM, Everall IP. Glial cell abnormalities in major psychiatric disorders: the evidence and implications. Brain Res Bull 2001;55:585-95.

[25] Cotter D, Mackay D, Landau S, Kerwin R, Everall I. Reduced glial cell density and neuronal size in the anterior cingulate cortex in major depressive disorder. Arch Gen Psychiatry 2001;58:545-53.

[26] Cotter D, Mackay D, Chana G, Beasley C, Landau S, Everall IP. Reduced neuronal size and glial cell density in area 9 of the dorsolateral prefrontal cortex in subjects with major depressive disorder. Cereb Cortex 2002;12:386-94.

[27] Öngür D, Drevets WC, Price JL. Glial reduction in the subgenual prefrontal cortex in mood disorders. Proc Natl Acad Sci U S A 1998;95:13290-5.

[28] Kugaya A, Sanacora G. Beyond monoamines: glutamatergic function in mood disorders. CNS Spectr 2005;10(10):808-19.

[29] Brambilla P, Perez J, Barale F, Schettini G, Soares JC. GABAergic dysfunction in mood disorders. Mol Psychiatry 2003;8:721-37.

[30] Zink M, Vollmayr B, Gebicke-Haerter PJ, Henn FA. Reduced expression of glutamate transporters vGluT1, EAAT2 and EAAT4 in learned helpless rats, an animal model of depression. Neuropharmacology 2010;58(2):465-73.

[31] Bromfield EB, Altshuler L, Leiderman DB, et al. Cerebral metabolism and depression in patients with complex partial seizures [published erratum appears in Arch Neurol 1992 Sep;49(9):976]. Arch Neurol 1992;49(6):617-23.

[32] Quiske A, Helmstaedter C, Lux S, Elger CE. Depression in patients with temporal lobe epilepsy is related to mesial temporal sclerosis. Epilepsy Res 2000;39(2): 121-5.

[33] Serles W, Li LM, Caramanos Z, et al. Relation of interictal spike frequency to 1HMRSI- measured NAA/Cr. Epilepsia 1999;40(12):1821-7.

[34] Guye M, Le Fur Y, Confort-Gouny S, et al. Metabolic and electrophysiological alterations in subtypes of temporal lobe epilepsy: a combined protonmagnetic resonance spectroscopic imaging and depth electrodes study. Epilepsia 2002;43(10): 1197-209.

[35] Gilliam FG, Maton BM, Martin RC, et al. Hippocampal 1H-MRSI correlates with severity of depression symptoms in temporal lobe epilepsy. Neurology 2007;68(5): 364-8.

[36] Schramm E,et al. Chronische und therapieresistente Depression.In:Voderholzer U,Hohagen F,ed.Therapie psychischer Erkrankungen.Munchen:Elsevier GmbH;2012.p183.

[37] Maguire J,Salpekar JA, Stress, seizure, depression and HPA axis targets for the treatment of epilepsy.Epilepsy Behav 2013;26:35262.

[38] Kanner AM. Current review in clinical science: depression in epilepsy: a neurobiologic perspective. Epilepsy Curr 2005; 5:21-27.

[39] Kanner AM, Tilwalli S, Smith MC, Bergen D, Palac S, Balabanov AJ, Byrne R. A presurgical history of depression is associated with a worse postsurgical seizure outcome following a temporal lobectomy. Neurology 2003;62(suppl 5):A389 (abst.).

[40] Berman RM, Cappiello A, Anand A, et al. Antidepressant effects of ketamine in depressed patients. Biol Psychiatry 2000;47:351-4.

[41] Zarate Jr CA, Payne JL, Quiroz J, et al. An open-label trial of riluzole in patients with treatment-resistant major depression. Am J Psychiatry 2004;161:171-4. 